\title{
ANÁLISES URBANAS DA CIDADE DE PRESIDENTE BERNARDES - SP
}

Anderson de Oliveira Ferreira Lima, Bruno Rafael Fernandes, Lívia de Oliveira Ferreira e Silva, Mayara Pissutti Albano

Universidade do Oeste Paulista - UNOESTE. Curso de Arquitetura e Urbanismo, Presidente Prudente - SP. E-mail: ma.albano@unoeste.br

\section{RESUMO}

A cidade de Presidente Bernardes, como muitas de sua região, desenvolveu-se devido ao incentivo da instalação da estação ferroviária e também por suas terras férteis, que atraíram muitas pessoas em busca de melhores condições de vida, favorecendo seu vertiginoso crescimento. Contudo, os períodos de crise por quais passou todo o país afetaram também a pequena cidade, que estagnada, se viu obrigada a mudar os caminhos de sua economia. As questões analíticas de seu espaço urbano são o ponto forte da presente pesquisa que busca, a partir das verificações a que se chegou deixar clara a urgente necessidade de se pontuar medidas para a mitigação dos problemas, aproveitando a escala ainda pequena da cidade para o devido controle de gestão e planejamento. Para tais análises, a metodologia empregada foi baseada em pesquisas bibliográficas, documentais e de campo.

Palavras-chave: Análise socioespacial. Estrutura urbana. Presidente Bernardes - SP.

\section{URBAN ANALYSIS OF THE CITY OF PRESIDENT BERNARDES - SP}

\begin{abstract}
The city of Presidente Bernardes, like many of his region, was developed due to the encouragement of the installation of the railway station and also for its fertile lands, which have attracted many people in search of better living conditions, favoring its rapid growth. However, periods of crisis which began throughout the country also affected the small town, which stagnated, was forced to change the paths of its economy. The analytical questions of its urban space are the strong point of this research that seeks, from the checks that have been reached make clear the urgent need to punctuate measures to mitigate the problems, taking advantage of the still small scale of the city to because management control and planning. For such analyzes, the methodology used was based on bibliographical, documentary research and field.
\end{abstract}

Keywords: Socio-spatial analysis. Urban structure. Presidente Bernardes - SP 


\section{INTRODUÇÃO E JUSTIFICATIVA}

O presente artigo visa tratar de questões analíticas do espaço da cidade de Presidente Bernardes - localizada no extremo oeste do estado - que dista aproximadamente 14 quilômetros de sua circunvizinha Presidente Prudente - denominada a capital do Oeste Paulista. Fundada em 12 de outubro de 1919, possui atualmente, segundo o senso do IBGE (2010), uma população de aproximadamente 13.544 habitantes.

Como muitos núcleos urbanos da região, a cidade cresceu devido ao incentivo da instalação da Estrada de Ferro. As terras férteis da primitiva gleba tornaram-se acessíveis aos interessados na compra dos lotes, que chegavam por meio dos trens da recém-inaugurada estação cujo nome - Presidente Bernardes - estendeu-se mais tarde ao município. A grande quantidade de pessoas que aqui chegava e se instalava em busca de melhores condições de vida favoreceu o seu vertiginoso crescimento (Prefeitura Municipal de Presidente Bernardes, 2006).

A locação da cidade seguiu as orientações da planta original, traçada por um engenheiro de uma companhia de colonização de São Paulo que atuava na região. Sem conhecer o terreno traçou-se uma planta plana, vindo às ruas a cair em terrenos acidentados, o que resultou nos aclives que existem ainda hoje na malha urbanas de configuração ortogonal. Pode-se inferir que a estruturação inicial da mesma ocorreu de maneiras diversas e sem planejamento adequado, o que não impede um planejamento a partir de então, muito menos justifica a continuidade de sua expansão de maneira desordenada (SANTOS, 2000).

Os períodos de crise por quais passou todo o país, afetaram também a pequena cidade, que sofreu grande processo de estagnação e viu-se obrigada a mudar os rumos de sua economia. O fortalecimento e surgimento de comércios, como em várias cidades da região, foi o fator determinante para a subsistência da mesma. Pode-se, a partir daí, observar uma brusca redução do papel da agricultura e da pecuária no panorama de sustentação econômica do município, o que se verifica ainda hoje - presença de comércios e serviços, seguidos da agropecuária e de pequenas indústrias movimentando a economia da cidade. A frequente instabilidade dos períodos atuais refletiu-se também na sua população que, não é de hoje, vêm sofrendo períodos de oscilação constante no número de habitantes.

As questões analíticas do espaço urbano de Presidente Bernardes são o ponto forte da presente pesquisa que busca, a partir das verificações a que se chegou deixar clara a urgente necessidade de se pontuar medidas para a mitigação dos problemas, aproveitando a escala ainda pequena da cidade para o devido controle de gestão e planejamento, tendo-se isto como o principal objetivo do estudo. 


\section{METODOLOGIA}

Como metodologia principal pretendeu-se a pesquisa bibliográfica e discussão de questões referentes a análises urbanas. Esse método de análise inicial é completado pelas observações in loco realizadas na cidade de Presidente Bernardes.

\section{ANÁLISES URBANAS}

As questões analíticas do espaço da cidade de Presidente Bernardes são referenciadas na presente pesquisa pelas assertivas e conceitos dos autores trabalhados, cada qual em sua abordagem particular das análises e estruturas urbanas. Faz-se aqui o paralelo entre as questões citadas pelos autores e as observações verificadas com relação à cidade.

\section{A Natureza Peculiar das Cidades - observações pela ótica de Jane Jacobs}

A vida social da cidade começa a acontecer nas calçadas - os lugares públicos onde ocorre o encontro e a reunião de pessoas de maneira íntima, como destaca inicialmente a autora. As calçadas, continua, são os "únicos elementos vitais e imprescindíveis da segurança, da vida pública e da criação de crianças nas cidades; [...] são parte da rua que cabe à circulação de pedestres e a muitos outros fins, cuja função fundamental é a manutenção da segurança urbana". (JACOBS, 2007, p. 29)

As calçadas da área central de Presidente Bernardes têm seu uso focado na circulação, desempenhando também a função de espaço de inter-relação através do contato entre as pessoas. Já as ruas e calçadas de bairros, no geral, servem tanto para a circulação - quando suas condições físicas permitem - como para a relação de encontro, podendo ainda servir de prolongamento do "quintal" para fins de lazer e conversas de fim de tarde, por exemplo, numa estreita apropriação do espaço público. Isso é geralmente observado nos bairros mais antigos da cidade, bem como a inversão de usos, quando a rua passa a ser usada como calçada. Verifica-se também, principalmente nos setores das classes mais baixas, a apropriação do espaço externo pelas crianças.

A maioria dos bairros constituintes do núcleo urbano é quase que exclusivamente de uso residencial. Contudo, nas aglomerações mais afastadas da área central podem-se observar edificações comerciais e de serviços que pontuam esses bairros ao longo de seu traçado. Jacobs (2007) descreve ainda ser o grande erro de o planejamento ortodoxo pensar nos bairros como modelos voltados para si, sendo unidades auto-suficientes. A falta de autonomia - econômica e social - é natural e necessária aos mesmos, já que são simplesmente integrantes das cidades. Isto 
é mais claramente observado através da "dependência" da área central por todos os bairros constituintes da cidade estudada, o que tem seus pontos benéficos, segundo a autora.

As áreas da cidade destinadas a espaços de suporte a equipamentos de lazer - quando presentes - são relativamente pequenas. Na maioria das vezes são somente gramadas e com pouca vegetação arbóreo-arbustiva. A praça central é a maior e mais abundante em área vegetativa da cidade, cujo valor histórico é visível ainda na atualidade. Já a praça da Igreja Matriz, também na área central, apesar das dimensões mais modestas, não se torna menos importante que a já citada. Os parques de bairro como discorre a autora, são locais efêmeros, cabendo às pessoas a freqüente utilidade dos mesmos, fazendo deles um sucesso ou condenando-os ao fracasso devido ao desuso.

Segundo Jacobs (2007) os geradores da diversidade urbana são os usos combinados, as quadras curtas, os prédios antigos e a necessidade de concentração. Na cidade analisada podemse observar muitos desses pontos nas diferentes áreas da mesma, entretanto, essas potencialidades não são, em sua maioria, aproveitadas. Sabe-se que o pleno entendimento da cidade se dá pela análise de sua totalidade e, para compreendê-la, é necessário admitir as diferentes combinações e misturas de usos, e não seus usos separados. A cidade em questão, de maneira geral, é rica na mistura de usos de sua área central, bem como as particularidades de outros setores - características e qualidades não utilizadas em sua máxima eficiência.

Pode-se ainda observar uma positiva interligação dos núcleos e espaços que compõem o traçado urbano da mesma, que possui relações de conexão entre seus bairros. Contudo, os diversos elementos dessa interligação deveriam ser mais bem estruturados. Embora haja o desencontro no traçado de alguns bairros, a cidade possui um desenho particular, quebrando-se a regularidade de sua malha, o que deveria ser usado como gerador de diversidade, potencializando os diferentes trajetos - tornando-os mais sensitivos, tirando proveito das quadras não muito longas, bem como da topografia que se torna elemento importante.

A presença de edificações de diferentes períodos nas áreas mais consolidadas ocorre de maneira constante, mesmo com as inevitáveis adequações desordenadas aos novos usos. Essa característica traz para o centro uma diversidade tanto de usos como de visuais. As edificações geralmente possuem usos residenciais no pavimento superior, sendo o andar térreo reservado aos usos de comércio e serviços. Já a grande quantidade de terrenos vazios e com edificações não finalizadas e sem uso pode, de certa maneira, prejudicar o potencial de diversidade de algumas áreas da cidade. 


\section{A Estrutura Urbana}

Villaça (2001) destaca a importância de se observar a cidade em sua totalidade com seus elementos que se inter-relacionam, definindo o referido espaço como a área a ser estudada levando-se em consideração todas as relações dentro e fora do mesmo.

O município de Presidente Bernardes, com aproximadamente 752.134 km² (IBGE, 2010), possui território de área proporcional ao de sua circunvizinha, Presidente Prudente. Todavia, seu perímetro urbano ocupa uma parcela relativamente pequena da grande extensão de terra (Figura 1). Pode-se aqui, compreender a diferença do espaço regional para o espaço intra-urbano, derivada também dos transportes e das comunicações, como coloca o autor (VILLAÇA, 2001, p. 20). O espaço "dentro" da cidade é composto ainda por dois tipos: o dos objetos - tudo o que é físico, criado ou não pelo homem - e o dos locais - onde os objetos são produzidos e consumidos. O espaço físico por si só tem grande influência no crescimento das cidades.

O crescimento físico das mesmas é impulsionado pela relação entre as vias regionais de transporte e sua estrutura, sendo estes apenas influenciadores em seu arranjo territorial e não os promotores do crescimento urbano. A definição da cidade se desenvolve, a princípio, a partir da disposição do setor viário, que define a circulação e os transportes, bem como partir das decisões das classes sociais, conscientes ou não de suas ações conjuntas. O estudo das localizações intraurbanas é privilegiado pela investigação das localizações das classes e sua articulação com os outros elementos da estrutura urbana, setorizando assim os usos das mesmas (VILLAÇA, 2001).

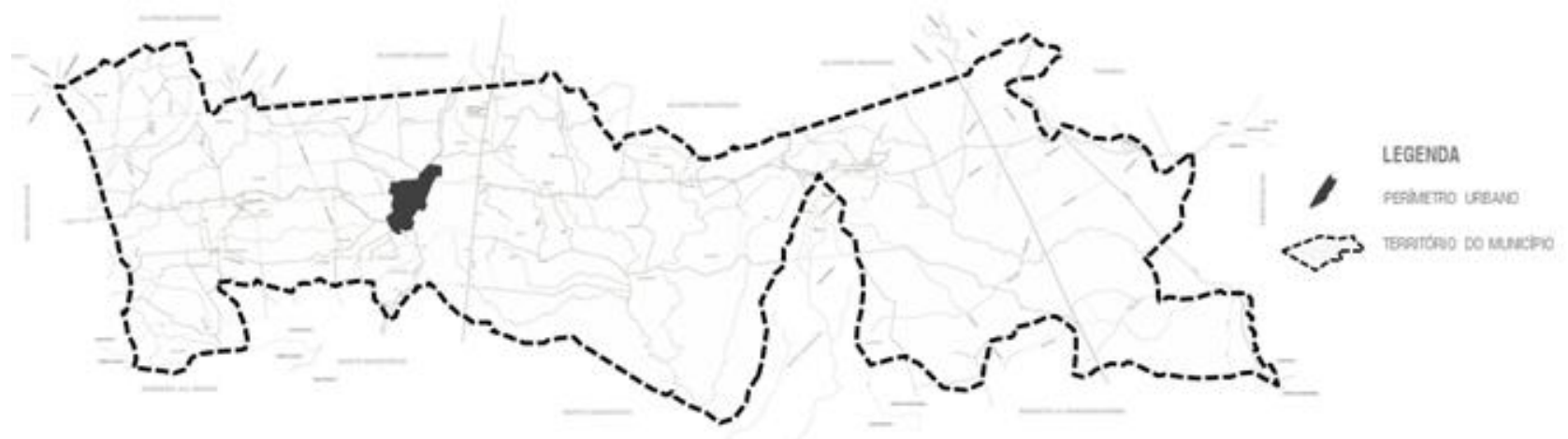

Figura 1. O município e sua mancha urbana

Fonte: Mapa Município - Site da Prefeitura Municipal. Organização: Autores, 2014.

Esta relação entre as vias de transporte e o crescimento físico das cidades, como destaca o autor, pode também ser observada de maneira muito forte na cidade de Presidente Bernardes. Desde a origem do povoado, as vias de transporte - antes a estrada e a ferrovia; hoje as vias de acesso e a rodovia - influenciaram em muitos aspectos, não somente para o crescimento do tecido urbano, mas atuando sobre o arranjo territorial desse crescimento. 
O estudo das principais metrópoles brasileiras, apontado por Villaça, possibilitou o entendimento da formação das mesmas que compartilham até os dias atuais os mesmos princípios e características de crescimento inicial - em setores de círculo - bem como importantes traços comuns de organização intra-urbana (2001, p.113). Verifica-se, então, que o crescimento de Presidente Bernardes se deu, e poderá dar-se através de diferentes direções, devido à possibilidade de expansão em todas as direções, permitida inclusive por suas características geográficas. A partir do exemplo de setores de círculo (Figura 2), observa-se de maneira clara a estrutura socioespacial que, de certa maneira, é mantida desde o traçado original da malha urbana. Mantêm-se a centralidade dos usos de comércio/serviços, enquanto que os setores residenciais desenvolvem-se ao seu redor.

Com relação às áreas de atração e a importância que o "sítio" exerce na estruturação intraurbana, verifica-se que a cidade se divide em pequenos setores que possuem diferentes atrativos, geralmente nos pontos altos da mesma. Já a área central se encontra em nível intermediário com relação ao contexto geral da cidade, proporcionando o fácil acesso por parte das aglomerações residenciais de seu entorno imediato, bem como o dinamismo gerado pela proximidade desses setores com diferentes tipos de usos. Os bairros de topografia inconstante, localizados, ainda, nas áreas mais afastadas do centro são, em sua maioria, desprovidos de atrativos que dinamizam sua estrutura interna, o que comprova a necessidade de se estimular as diferentes particularidades da estrutura urbana.

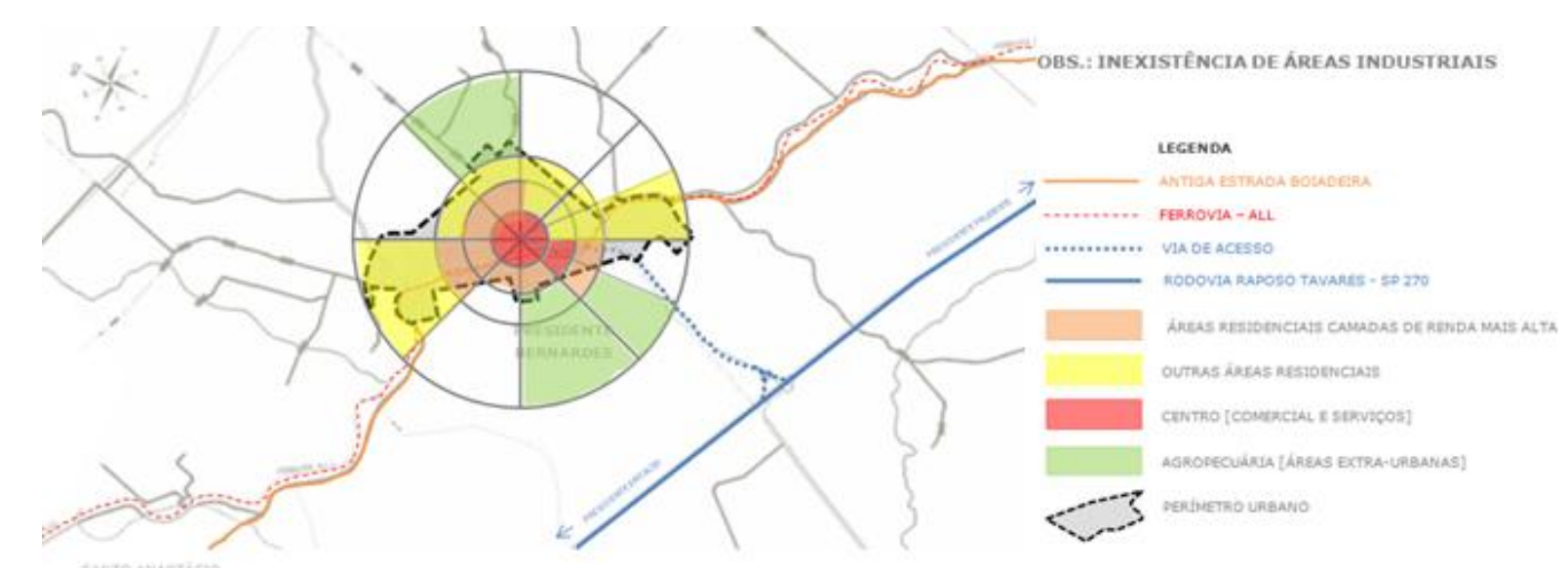

Figura 2. Gráfico da estrutura socioespacial de Presidente Bernardes

Fonte: Mapa dos distritos e bairros da cidade - Presidente Bernardes, 2009. Organização: Autores, 2014.

A disputa por determinadas localizações no espaço intra-urbano, segundo Villaça (2001, p.141) ocorre através da transformação seletiva de determinados locais da cidade, bem como da atribuição de valores aos mesmos pela especulação imobiliária. Esses acontecimentos afetam, mesmo que de maneira espontânea, toda a estrutura da cidade - a segregação urbana cria os 
diversos espaços "isolados" da mesma, cujos interesses comuns condicionam as aglomerações de classes em determinados locais. O espaço atua também como um mecanismo de exclusão e um meio para a dominação social, econômica e política (VILLAÇA, 2001, p.143).

Na cidade de Presidente Bernardes a segregação pode ser observada quando se analisa a área ao sul da linha férrea que, desde o surgimento do município, é considerada privilegiada por sua localização geográfica e, principalmente, pela proximidade da mesma com a área central fatores estes que contribuem para a formação de núcleos de classes com interesses comuns dominando esses espaços. Esses bairros considerados mais "nobres" ocupam um mesmo setor dentro da malha urbana e atualmente crescem de maneira significativa, com relativo número de novas edificações concentradas ao redor da área preexistente.

Sendo ainda a única contentora do suporte para as necessidades dos habitantes da cidade, a região central concentra em sua volta grande quantidade de residências de classe média e algumas poucas de classe alta - que está migrando para a área além linha da cidade, isolando-se dos demais bairros (Figura 3). Adentra-se à discussão de um fator das grandes metrópoles - a segregação numa mesma região e a manutenção de mesma direção de deslocamento por parte da classe de maior poder aquisitivo, que limita e encerra o crescimento do seu setor em sua volta, impedindo às outras classes de juntar-se a si física e socialmente. Referenciam-se as análises da cidade em questão com outras descrições do autor, quando o mesmo aborda o fato de haver bairros populares inseridos na região de concentração das camadas de alta renda que nada alteram o processo de diferenciada produção e consumo do espaço urbano - mesmo com a presença das camadas mais pobres no espaço dos mais ricos, a grande maioria dessas camadas ainda ocupa o "lado de lá" da cidade e as periferias afastadas.

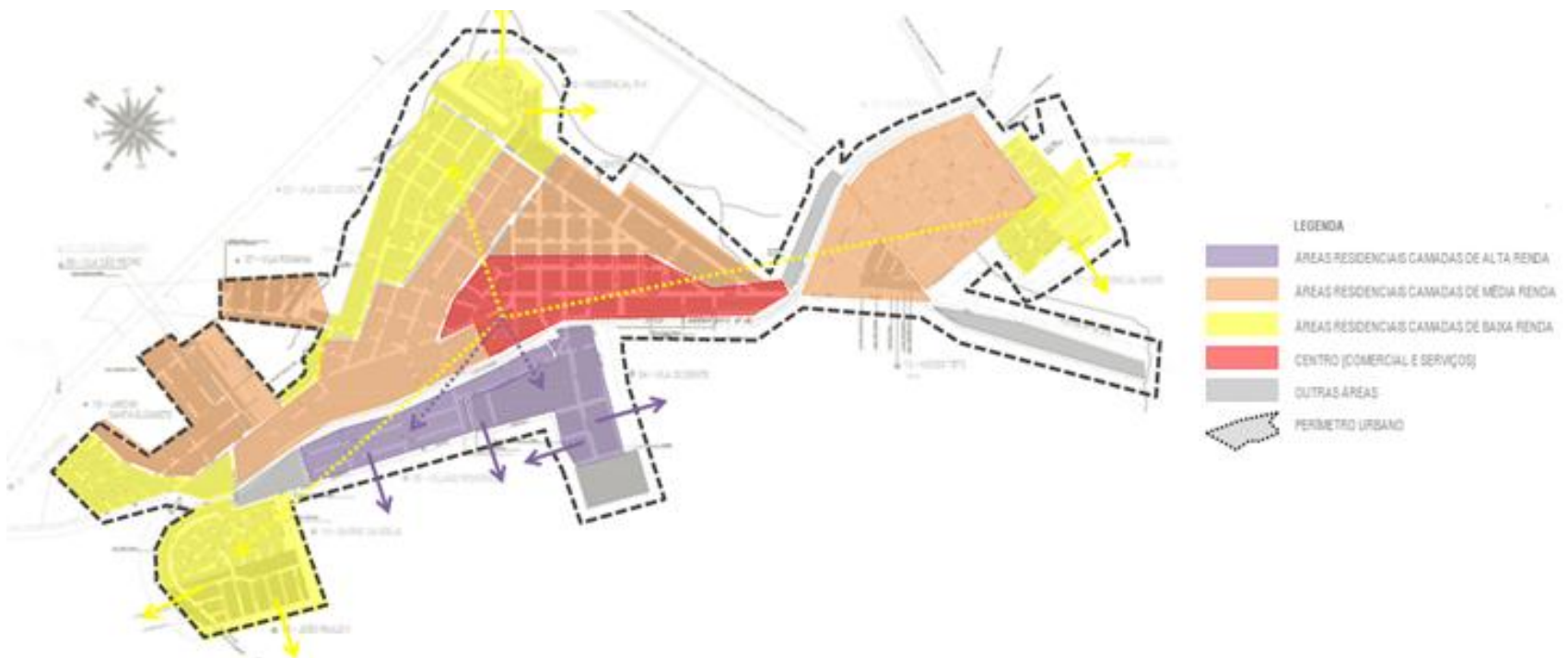

Figura 3. Mapa de distribuição das classes sociais e suas direções de expansão Fonte: Mapa Urbano da Prefeitura - distritos e bairros da cidade, 2009. Organização: Autores, 2014. 
A área central como sendo fruto do movimento da cidade e o objeto de disputa entre as classes, torna-se mais acessível a uns que a outros. As transformações territoriais por que passaram e continuam passando os centros das cidades são frutos dessa disputa, destaca Villaça (2001). A partir de análises e levantamento de dados, pôde-se concluir que a área central da cidade em questão é, ainda na atualidade, contentora de grande parcela de edificações com usos residenciais - o centro de comércio propriamente dito divide espaço com estabelecimentos de serviço e usos residenciais pontuados pelas quadras. Na medida em que se adentra aos bairros adjacentes à área central, os usos de comércio e serviços passam a ser excepcionais.

Na cidade analisada não há a presença nítida de subcentros propriamente ditos - já que a concentração de usos variados atendendo a necessidade de população local não se observa de maneira estruturada em nenhum setor da mesma. A forte relação de interdependência com o centro é ainda claramente observada o que, a priori, exclui a tendência pra a formação de um "centro novo" na cidade. Em determinados bairros ocorre, de maneira pontual, a presença de alguns comércios e serviços locais, identificando uma precoce inclinação para a criação e estruturação de futuros subcentros.

\section{CONSIDERAÇÕES FINAIS}

Procurou-se no presente artigo discutir questões urbanas através de um panorama geral da cidade analisada, no que diz respeito ao que está sendo produzido - de maneira desordenada - e seu impacto no decorrer dos anos. O caminho adequado de planejamento para a cidade deve ser fundamentado na consciência da cidade real, que pode ser conhecida através de levantamentos socioespaciais. Para tanto, a discussão apresentada se torna uma ferramenta que colabora para a descoberta das reais necessidades da cidade e de sua população. Com relação à cidade de Presidente Bernardes, aproveitar sua escala, ainda pequena, para o devido controle de gestão e planejamento - no presente e no futuro - será, ou pelo menos deveria ser a atitude mais sensata a se tomar na atualidade, e, acrescenta-se aqui, com caráter de urgência.

\section{REFERÊNCIAS BIBLIOGRÁFICAS}

Prefeitura Municipal de Presidente Bernardes, SP. Disponível em: http://www.presidentebernardes.sp.gov.br/. Acesso em 21 de fevereiro de 2014.

GIESBRECHT, R. M., Presidente Bernardes (antiga Guarucaia). Disponível em: http://www.estacoesferroviarias.com.br/p/presbernardes.htm. Acesso em 21 de fevereiro de 2014. 
JACOBS, J. M., Morte e Vida de Grandes Cidades. São Paulo: Martins Fontes, 2007.

SANTOS, W., Presidente Bernardes: História de sua Fundação. Presidente Prudente: [s.n.], 2000. Villaça, F., Espaço Intra-Urbano no Brasil. São Paulo: Studio Nobel, 2001. 